\title{
Lack of Neurotrophin 3 Causes Losses of Both Classes of Spiral Ganglion Neurons in the Cochlea in a Region-Specific Fashion
}

\author{
Bernd Fritzsch, ${ }^{1}$ Isabel Fariñas, ${ }^{2}$ and Louis F. Reichardt ${ }^{2}$ \\ ${ }^{1}$ Department of Biomedical Sciences, Creighton University, Omaha, Nebraska 68178, and 2 Program in Neuroscience, \\ Department of Physiology and Howard Hughes Medical Institute, University of California, \\ San Francisco, California 94143-0724
}

\begin{abstract}
Essential functions of neurotrophin 3 (NT-3) in regulating afferent and efferent innervation of the cochlea have been characterized by comparison of normal and NT-3 mutant mice. NT-3 deficiency has striking, region-specific effects, with complete loss of sensory neurons in the basal turn and dramatic but incomplete neuronal loss in the middle and apical turns. The sensory innervation of inner and outer hair cells was reorganized in mutant animals. Instead of a strictly radial pattern of innervation, the axons of remaining sensory neurons projected spirally along the row of inner hair cells to innervate even the most basal inner hair cells. Innervation of outer hair cells was strongly reduced overall and was not detected in the basal turn.
\end{abstract}

The presence of fibers extending to both inner and outer hair cells suggests that subsets of types I and II sensory neurons survive in the absence of NT-3. Likewise, projections of the cochlea to auditory nuclei of the brainstem were attenuated but otherwise present. Equally striking changes in efferent innervation were observed in mutant animals that closely mimicked the abnormal sensory innervation pattern. Despite these impressive innervation deficiencies, the morphology of the organ of Corti and the development of inner and outer hair cells appeared comparatively normal.

Key words: NT-3 mutants; inner ear; cochlea; spiral ganglion; innervation; ear development
The inner ear contains vestibular structures responsible for regulation of balance and cochlear structures involved in hearing. Numerous studies have characterized the distribution and documented the importance of the neurotrophins, brain-derived neurotrophic factor (BDNF) and neurotrophin 3 (NT-3), and their respective receptor tyrosine kinases, TrkB and TrkC, in the development of these sensory organs. Sensory epithelia of the inner ear express BDNF and NT-3, and their receptors are expressed by vestibular and cochlear sensory neurons (Pirvola et al., 1994; Schecterson and Bothwell, 1994; Wheeler et al., 1994). Analyses of mice with targeted mutations have shown that these molecules have essential and complementary roles in the development of these systems, with NT-3 being more important for the cochlear system and BDNF for the vestibular system (Ernfors et al., 1994, 1995; Fariñas et al., 1994; Jones et al., 1994; Fritzsch et al., 1995, 1997a,b; Schimmang et al., 1995; Bianchi et al., 1996).

The cochlea is a spiral duct located within the inner ear that contains the organ of Corti, a specialized epithelium involved in the reception of auditory stimuli. The organ of Corti consists of two types of sensory receptor cells, or hair cells, arranged along the entire extent of the cochlea. The inner hair cells (IHCs) form a single row, whereas the outer hair cells (OHCs) are arranged in three parallel rows. The organ of Corti receives afferent inner-

Received Jan. 13, 1997; revised May 29, 1997; accepted June 3, 1997.

This work was supported in part by National Institute of Deafness and Other Communication Disorders Grant P 50 DC 00215 to B.F. and National Institute of Mental Health Grant 48200 to L.F.R. I.F. is the recipient of a long-term fellowship from the Human Frontier Science Program organization. L.F.R. is an Investigator of the Howard Hughes Medical Institute. B.F. thanks Mrs. C. Miller for excellent assistance with the transmission electron microscopic and scanning electron microscopic preparations and for darkroom work and Mrs. M. Christensen for help with the immunocytochemistry.

Correspondence should be addressed to Dr. Bernd Fritzsch, Department of Biomedical Sciences, Creighton University, Omaha, NE 68178.

Copyright (C) 1997 Society for Neuroscience $0270-6474 / 97 / 176213-13 \$ 05.00 / 0$ vation from sensory neurons of the cochlear (spiral) ganglion, which convey the auditory information from the hair cells to auditory (cochlear) nuclei in the brainstem. Two distinct populations of spiral ganglion neurons have been recognized, a majority (92-94\%) of type I ganglion cells, which specifically innervate IHCs, and a small population $(6-8 \%)$ of type II ganglion cells, which supply the more numerous OHC population (Romand and Romand, 1987). Although type I spiral ganglion cells and their innervation of the IHCs are known to be important for conducting sound-generated signals from the cochlea to the brain, the functions of type II spiral ganglion cells are not well understood (Walsh and Romand, 1992), and their projections have only recently been revealed (Berglund et al., 1996). An additional third type of ganglion cell is sometimes described in development and in adult pathological cases (Ryugo, 1992; Sobkowicz, 1992). In addition, the organ of Corti also receives efferent innervation from neurons in the olivocochlear nucleus located in the brainstem (Fritzsch, 1996).

In NT-3 mutants, $\sim 85 \%$ of cochlear neurons are lost (Fariñas et al., 1994; Ernfors et al., 1995), and it has been suggested that all type I cells would be selectively dependent on NT-3 (Ernfors et al., 1995). In the present study we have analyzed the patterns of innervation of the cochlea in NT-3-deficient neonatal mice. Results show that effects of NT-3 deficiency on spiral ganglion cell survival and innervation differ among cochlear regions but are not selective for a particular ganglion cell type. In addition, despite the absence of $85 \%$ of the cochlear neurons, the remaining neurons reorganize their projections to supply fibers to areas devoid of cochlear neurons. Moreover, the sensory epithelium of the mutants appears normal, even in areas where innervation is completely absent.

\section{MATERIALS AND METHODS}

Animals. For this study we used 11 newborn NT-3-deficient mice and 11 wild-type littermates. The NT-3 mutant mice used for these studies were 
generated by targeted replacement of the NT-3-coding exon with a construct containing a lac Z gene cDNA and the PKCneo marker (Fariñas et al., 1994). Animals were fixed at birth by transcardiac perfusion with $4 \%$ paraformaldehyde in $0.1 \mathrm{~m}$ phosphate buffer, $\mathrm{pH} 7.3$, and kept in the same fixative solution. Animals were genotyped by DNA blot analysis as described previously (Fariñas et al., 1994).

DiI labeling. The initial morphological analysis was performed in a double-blind manner using coded specimens. Heads from coded neonate littermates were split sagittally, and DiI-soaked filter strips were applied into the brainstem alar plate of one side to label eighth nerve afferent fibers to the inner ear or into the olivo-cochlear efferent bundle of the contralateral side near the floor plate to label the efferent fibers (Fritzsch and Nichols, 1993). After an appropriate diff usion time of $3-5 \mathrm{~d}$ at $37^{\circ} \mathrm{C}$, the ears were dissected, and intact cochleae were examined with a compound epifluorescence microscope. Pictures were taken on 100 ASA TechPan film, and/or images were grabbed with a cooled CCD camera and processed by using a deconvolution technique (Vaytek and ImagePro software, Iowa City, IA). In one animal with a partial filling of afferents, nerve fibers and their terminals were deconvoluted, and a top view was reconstructed by collapsing the images (see Fig. $4 d$ ). After the initial analysis showed a clear difference in patterns of cochlear innervation among different animals in the coded batch (see Fig. 2a,c), four additional NT-3 mutant mice and four control mice from two more litters were investigated in an unblinded fashion.

The projection of the cochlea to the brainstem was studied in three NT-3 mutant mice and three control littermates by inserting DiI into the modiolus to label the entire cochlear projection (one animal each) or inserting DiI into the basal turn alone. In each case we checked the injections by examining the cochlea (see Fig. 6 , insets). The brains were embedded in gelatin, sectioned on a vibratome at $100 \mu \mathrm{m}$, and viewed with epifluorescence. Nuclei were counterstained using Hoechst stain. Photographs were taken as described above.

Immunocytochemistry. To reveal the general pattern of innervation, cochleae from one NT-3 mutant and one control littermate were stained as whole mounts with the antiacetylated tubulin monoclonal antibody (mAb) 6-11B1, which stains all nerve fibers (Easter et al., 1993). Inner ears were dissected out, defatted, and incubated in primary antibody (6-11B1, 1:500; T-6793, Sigma, St. Louis, MO) for $24 \mathrm{hr}$. The specimens were incubated with HRP-conjugated secondary antibody and reacted with diaminobenzidine $(1 \mathrm{mg} / \mathrm{ml})$ and $\mathrm{H}_{2} \mathrm{O}_{2}$ until fibers could be identified. Then cochleae were mounted and photographed as outlined above.

Transmission electron microscopic analysis. The ears of one neonatal NT-3-deficient mouse and one control littermate were dissected, osmicated in $1 \% \mathrm{OsO}_{4}$ for $1 \mathrm{hr}$, dehydrated, and embedded in epoxy resin. Semithin and ultrathin sections were taken at the base, the middle turn, and the apex and viewed with a light microscope or an electron microscope, respectively. The dimensions of the cochlea were measured using a CCD camera and ImagePro software (data not shown). Ultrathin sections were viewed in a Phillips CM10 microscope, and photomicrographs were taken at various magnifications.

Scanning electron microscopic analysis. The two ears of an NT-3 mutant mouse and a wild-type littermate were prepared for scanning electron
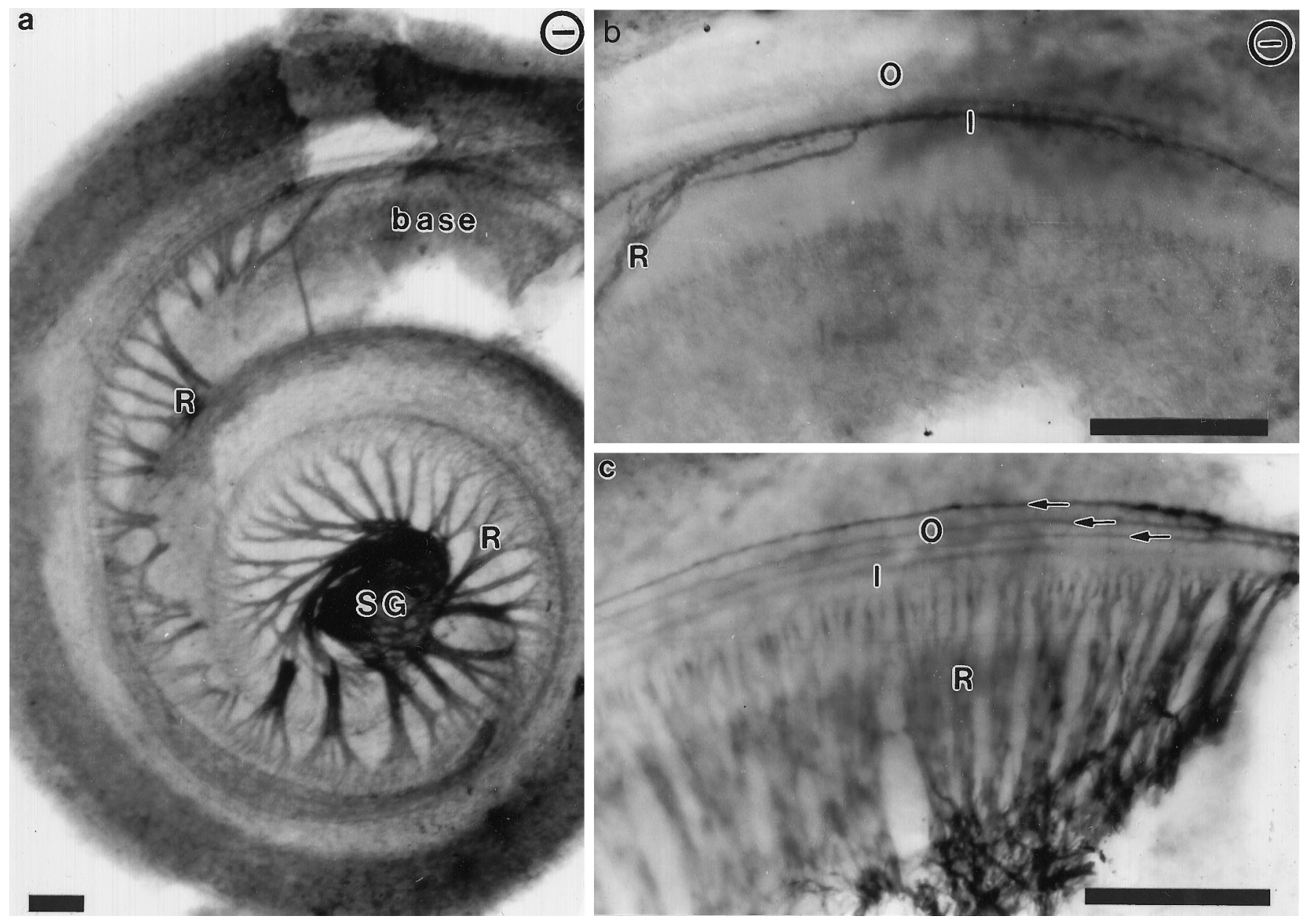

Figure 1. Patterns of cochlear innervation in whole mounts of newborn wild-type and NT-3 mutant homozygotes. An mAb to acetylated tubulin was used to reveal the nerve fiber patterns in a whole-mounted cochlea of a newborn NT-3 mutant $(a)$, in the basal turn of a newborn NT-3 mutant $(b)$, and in a control littermate $(c)$. In the cochlea of the NT-3 mutant, spiral ganglion cells $(S G)$ are present in the middle turn and extend their fibers to the apical turn. No radial fibers $(R)$ exist near the basal turn. However, fibers extend from the middle turn spiral ganglion cells along the inner hair cells of the base $(b)$ but do not extend to the layer of outer hair cells. In contrast, in the control littermate a dense radial fiber innervation is seen near the base (c), which extends along inner hair cells $(I)$ and all three rows (arrows) of outer hair cells $(O)$. $\ominus$, NT-3 mutant in this and all following figures. Scale bars, $100 \mu \mathrm{m}$. 


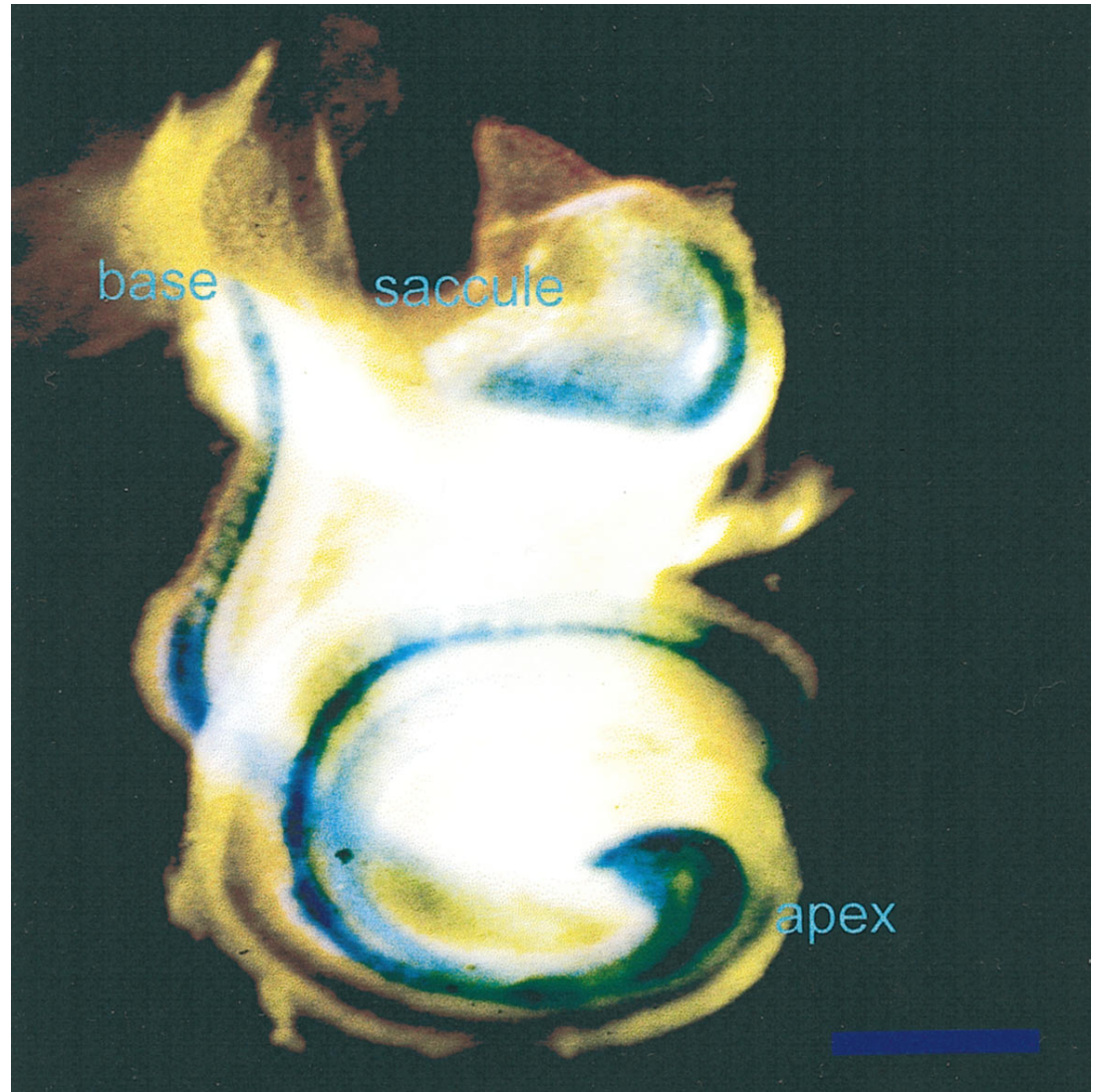

Figure 2. Distribution of $\beta$-galactosidase in the wholemounted cochlea of a newborn mouse heterozygous for the targeted replacement of the NT-3 coding exon with a construct containing a lac Z gene cDNA. Reporter expression is an indicator of the endogenous pattern of NT-3 expression. Reaction product is visible throughout the cochlea. The reaction is most prominent in the apex but also is prominent in the middle and basal turns. Reaction product is visible in the saccular sensory epithelium, but no labeling is apparent in the spiral ganglion. Scale bar, $1 \mathrm{~mm}$. microscopic analysis as described (Fritzsch et al., 1995). Briefly, cochleae were removed, osmicated, and divided into basal, middle, and apical turns. The tectorial membrane, Reissners membrane, and the stria vascularis were removed with microscissors. The pieces of the cochlea were critical point-dried, mounted, sputter-coated with gold-palladium, and viewed in a Hitachi scanning electron microscope.

$\beta$-Galactosidase (lac Z) reporter gene expression. The distribution of lac $\mathrm{Z}$ in the ears of two NT-3 heterozygous animals was determined using the X-galactosidase (X-Gal) reaction (Lazik et al., 1996). Briefly, the dissected ears were reacted overnight at $37^{\circ} \mathrm{C}$ in 1 part X-Gal added to 19 parts of a solution of $20 \mathrm{~mm}$ potassium ferrocyanide, $20 \mathrm{~mm}$ potassium ferricyanide, $2 \mathrm{~mm} \mathrm{MgCl}_{2}, 0.02 \% \mathrm{NP}-40$, and $0.01 \%$ sodium deoxycholate. The cochleae were mounted whole and photographed using a yellow filter to enhance visibility.

\section{RESULTS}

Initial characterization of the overall innervation patterns of the inner ear in normal and mutant mice are visualized in Figure 1, where isolated cochleae of newborn animals were labeled with a monoclonal antibody to acetylated tubulin, which permits visualization of the entire innervation pattern. Comparison of the innervation patterns in mutant (Fig. 1a,b) and control (Fig. 1c) animals shows that there is a dramatic reduction and reorganization of the overall innervation in mutant animals, with deficits particularly profound in the basal turn.

Comparison of this pattern of innervation with the pattern of NT-3 expression as revealed through the lacZ reporter at this developmental time (Fig. 2) does not show a match to this apparent region-specific reduction of spiral neurons. Clearly, lac Z reaction is most prominent in the apex but is also found in all three rows of hair cells as well as in the greater epithelial ridge in all parts of the cochlea. NT-3 expression is not seen, however, in the spiral ganglion. Because the pattern of NT-3 expression may change over the course of development, the lack of precise correlation between NT-3 expression and nerve innervation at any single period in development is not entirely unexpected. Earlier stages need to be examined to reveal more details of the NT-3 distribution and to understand how the NT-3 expression pattern relates to the apparent region-specific reduction of spiral ganglion cells.

\section{Afferent innervation}

To study the afferent innervation of the inner ear by cochlear neurons, we labeled their fibers by applying DiI to the alar plate of the brainstem, where their fibers terminate centrally. The overall patterns of afferent innervation seen in cochlear whole mounts of wild-type and mutant animals are shown in Figure 3. In wild-type animals, ganglion neurons in different parts of the cochlea project radially, giving rise to an array of closely spaced axonal bundles extending centrif ugally to reach the basilar membrane underlying the sensory epithelium. Most afferent fibers reach only to the row of IHCs. In addition, a proportion of the radial fibers project past the row of IHCs, cross the tunnel of Corti, and then turn to project toward the base in a spiral way below the rows of OHCs (Figs. $3 a, b, 4 b, 5 b$, arrows). In contrast, reduced numbers of radial and spiral fibers were seen in the middle and apical turns, and radial fibers were completely absent from the basal turn of the cochleae of mutant animals (Fig. 3). Consistently, a reduction in the number and density of spiral ganglion neurons in the middle and apical turns and an apparent complete depletion in the basal turn were also seen (Fig. 3, compare $a, c)$. These observations demonstrate that the neuronal deficit caused by the lack of NT-3 is not homogeneously distributed along the extent of the cochlea. The gradient of neuronal 

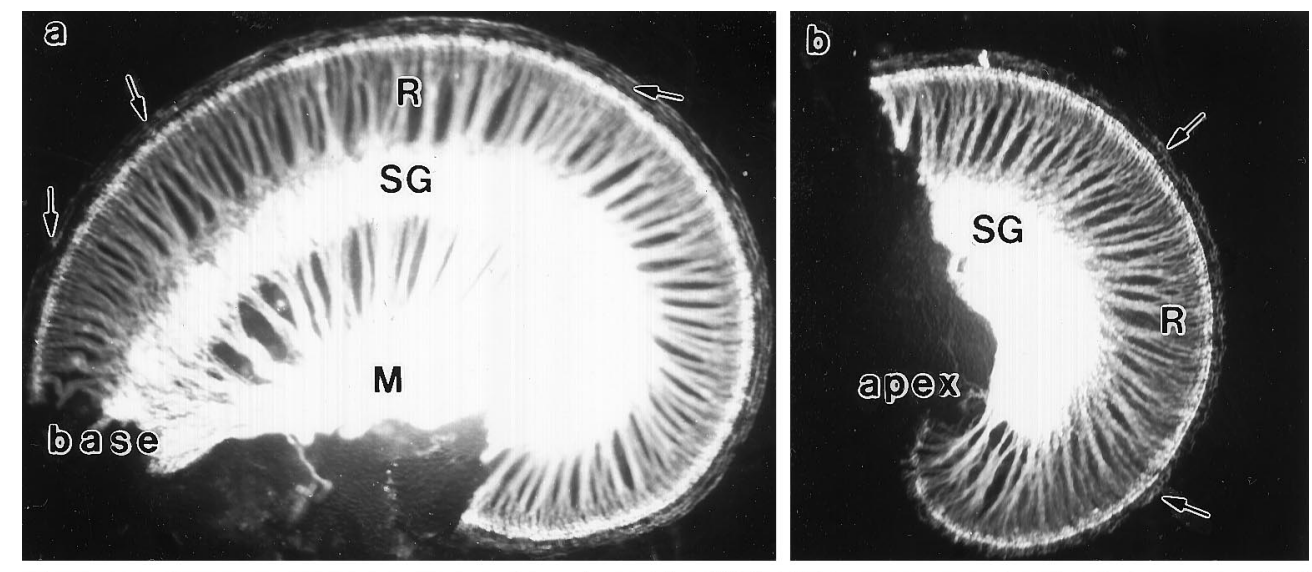
Figure 3. DiI-labeling patterns of affer-
ent innervation of the cochlea in newborn wild-type and NT-3-deficient mice. These images show differences in the pattern of innervation between a control $(a, b)$ and an NT-3-deficient littermate $(c, d)$. DiI was implanted in the eighth nerve afferents in the brainstem and diffused for $4.5 \mathrm{~d}$ at $37^{\circ} \mathrm{C}$. The cochlea was split into a basal $(a, c)$ and an apical $(b$, $d)$ half. Note the change of course of radial fibers $(R)$ in the NT-3 mutant littermate near the base $(a)$ and the apex (b). There is a complete absence of the spiral ganglia $(S G)$ in the basal half turn (c) and some reduction near the apex (d). However, fibers extend along the inner hair cells to the very tip of the base. $M$, Modiolus. Scale bar, $100 \mu \mathrm{m}$ for all images.
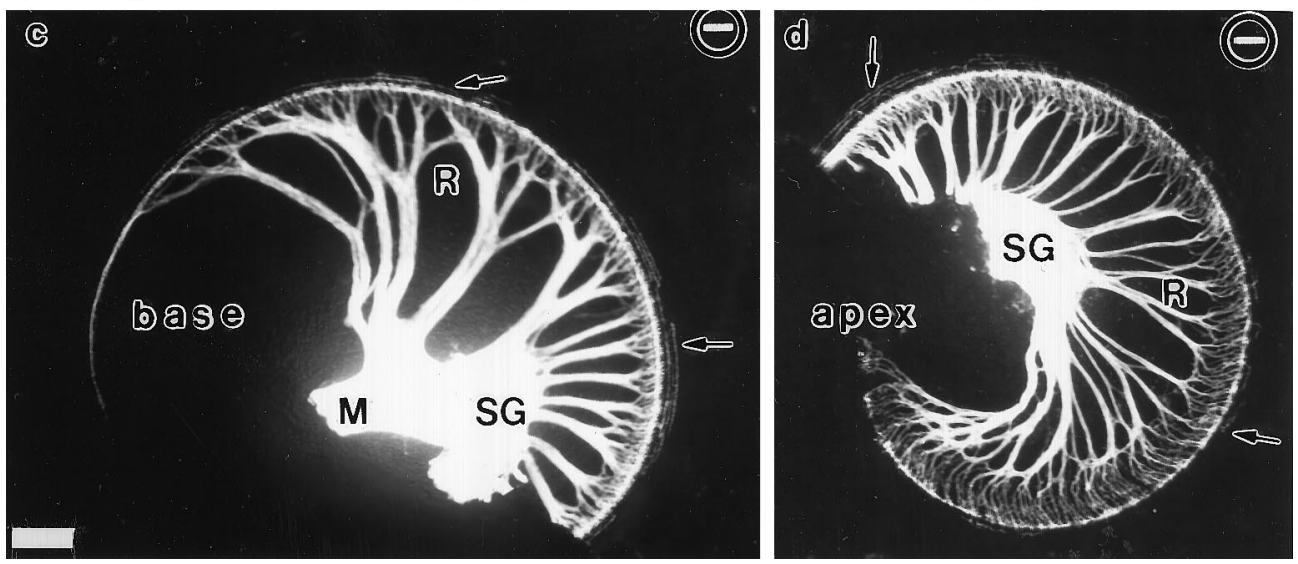

dependency on this neurotrophin revealed in these photographs is consistent with the previously reported basal-to-apical gradient of NT-3 expression during development (Pirvola et al., 1992). However, our X-Gal-reacted ears show only a slight overall increase in the expression of the reporter in the apex (Fig. 2). Clearly, more detailed data are needed on the changes of NT-3 expression during embryonic development.

Probably because of the overall paucity of radial fibers, and their absence in the basal turn, a remarkable redistribution of fibers was observed in the cochleae of NT-3-deficient mice (Fig. 3). Some radial fibers in the part of the middle turn of the cochlea closer to the basal turn, and to a lesser extent in the apical turn, were seen shifting their trajectory (Figs. 3, 4a,b). These redirected middle turn fibers formed a unique bundle that laterally diverged from the strict radial trajectory to project basally and reach the cochlear epithelium of the basal turn. Moreover, these fibers entered the organ of Corti and ran along the extent of the basal turn in a spiral trajectory below the row of IHCs (Figs. $4 a-d$ ). Although exchanges of afferent axons between radial bundles are frequently observed in control animals (Fig. 3a,b), these fiber exchanges always occur in close proximity to the sensory epithelium. In contrast, in the cochleae of NT-3 mutants the reorientation occurs at significant distances from the sensory epithelium.

The cochlea contains a single row of inner hair cells and three rows of outer hair cells, each of which receive afferent innervation in normal animals. Results presented in Figures 4 and 5 document that there are heterogenous effects of the lack of NT-3 on sensory afferent supply to these different sensory epithelial cell populations in different regions of the cochlea. In wild-type animals (Fig. 5a,c), afferent fibers revealed by DiI labeling of the eighth nerve innervate profusely the inner hair cells in all regions of the cochlea. Many fibers also cross the tunnel of Corti and supply all three rows of outer hair cells in all regions except the apical region, where fibers have not reached yet the third row of outer hair cells (see Fig. $5 c$ ). In mutant animals, fibers reaching the row of IHCs were seen in all parts of the cochlea (Fig. $5 b, d$ ). In the basal turn, however, where radial bundles were absent, axons reached the sensory epithelium in the unusual bundles of redistributed fibers described above and traveled in a spiral bundle to extend along the entire row of inner hair cells as described above (Fig. 4a, $b$; also see Fig. $5 b$ ). To individually analyze fibers that reach the row of IHC we labeled just a few afferents by applying a very small crystal of DiI to the cochlear nuclei (Fig. $4 c, d$ ). Some fibers could be followed in the middle and basal turns and were seen running along the neuronal side of the IHCs for about $8-12$ cells. The innervation of OHCs was differentially affected in the different parts of the cochlea by the absence of NT-3. In the apical region, no striking differences in the incomplete fiber supply to outer hair cells were found between wild-type and mutant animals (Fig. 5, compare $c, d$ ). In the middle turn, however, differences were apparent (Fig. 5, compare $a, b$ ). In mutant animals (Fig. 5b), fibers were seen reaching the first row of OHCs and, occasionally, extending to all three rows. However, unlike in normal animals (Fig. 5a), the few fibers that extended to all rows in the mutants did so following an irregular pattern running on either sides of all three rows of OHCs (Fig. 5b). Even more striking deficiencies were seen in the basal turn of cochleae derived from NT-3 mutants, in which the outer hair cells received no detectable fiber supply (Fig. $4 b-d)$ or, rarely, a single fiber. In general, the innervation of 

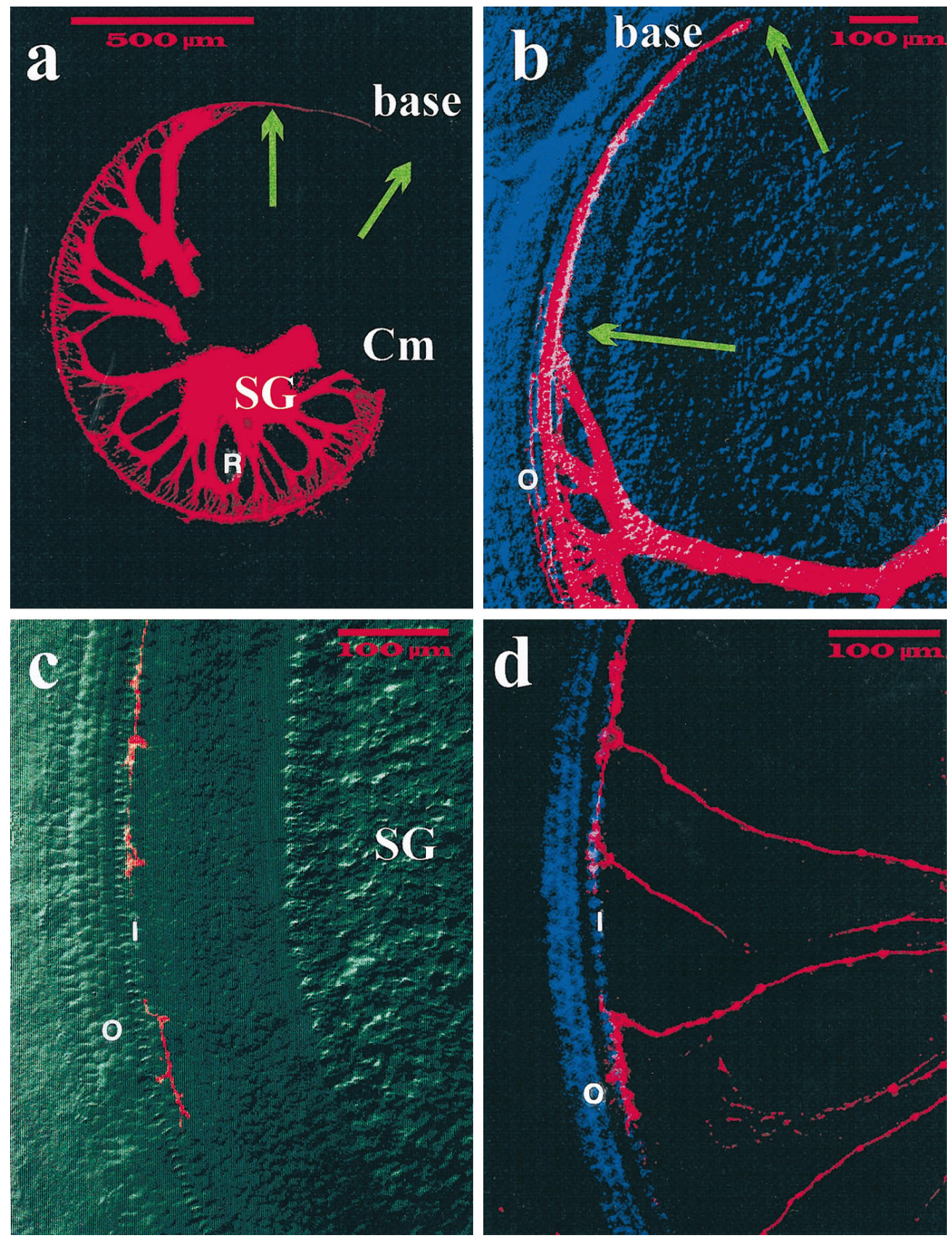

Figure 4. Distribution of sensory afferent fibers in the basal turn of P0 NT-3 mutant homozygotes. All afferents $(a, b)$ and subsets of afferents $(c, d)$ were filled with DiI from the brainstem. Note $a$ that the basal turn of the cochlea (base) lacks spiral ganglion cells $(S G)$ and radial fibers $(R)$, both of which are present in the middle turn $(\mathrm{Cm})$. Nevertheless, fibers extend along inner hair cells toward the base (arrows). As illustrated $b$, few fibers extend to outer hair cells $(O)$ near the middle turn. Selective labeling reveals the distribution of individual afferents in the middle basal turn $(c, d)$. Note that the terminal arbor of each afferent fiber is restricted to several inner hair cells $(I)$ with no processes crossing to the three rows of outer hair cells $(O)$, which appear normally developed in this differential interference contrast $(c)$ or fluorescence image $(d)$. Scale bar, 500 $\mu \mathrm{m}$ for all images.

OHCs was highly variable among animals, both in pattern and apparent density, but nonetheless, the lack of NT-3 caused very clear deficiencies. In conclusion, in the cochleae of NT3-deficient neonatal mice, all IHCs appear to be innervated either by the appropriate radial fibers or by fibers originating in other regions of the cochlea. Compared with normal animals, this innervation is significantly reduced. In contrast, many OHCs do not receive at all afferent fibers in the mutants. The reduced fiber supply to OHCs is particularly striking in the basal turn and, to a lesser extent, in the apex.

Despite this reduction in afferent supply in NT-3 mutants, the central projection to the cochlear nuclei was comparable to that of control littermates and seemed to cover much of the same area of the cochlear nuclei as judged by the Hoechst-stained cyotology (Fig. 6a-c). Nevertheless, there was a reduction in fiber density, especially in the most dorsal aspect of the cochlear nucleus in the mutants (Fig. 6c). This was particularly apparent in animals with a selective dye application to the basal turn (Fig. 6d,f, insets). These applications also served to control for the position of the ganglion neurons providing afferent fibers to the basal turn. Those neurons were found to be in the middle turn spiral ganglion (Fig. $6 g, h$ ). In conclusion, although the topology of the central afferent projection in mutant mice was comparatively normal and even reached the most dorsal, high-frequency, aspect of the cochlear nuclei (Fig. $6 d-f$ ), the density was reduced in the NT-3 mutant in this area (Fig. $6 c, f$ ).

\section{Efferent innervation}

Selective DiI labeling of the olivocochlear efferents in the cochleae of wild-type mice revealed the usual intraganglionic spiral 

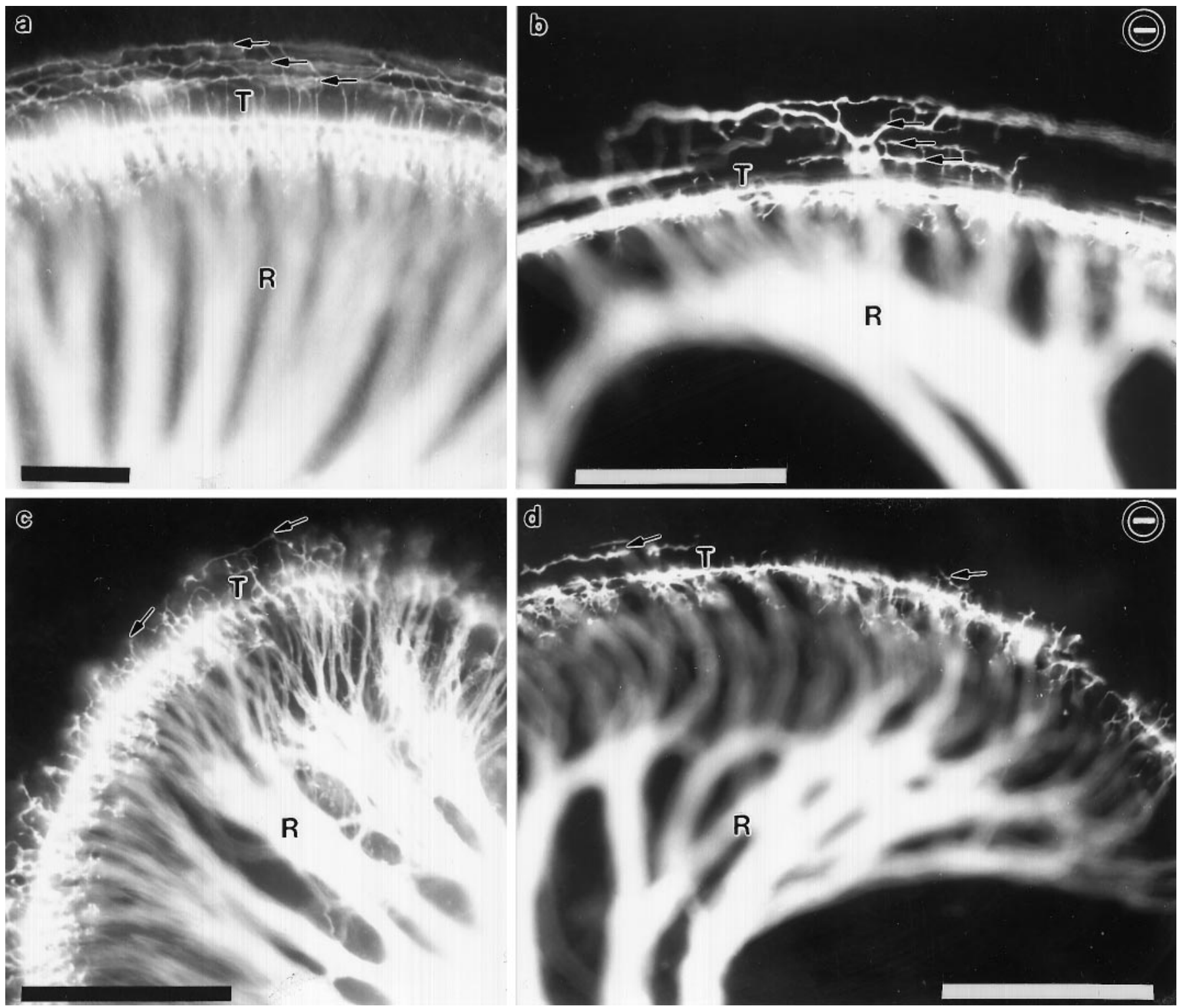

Figure 5. Comparison of afferent innervation to the middle and apical turns in newborn wild-type and NT-3 mutant mice. The distribution of afferents to the middle turn $(a, b)$ and the apex $(c, d)$ is shown for a control $(a, c)$ and an NT-3 deficient littermate $(b, d)$. Note the numerous fibers that extend beyond the inner hair cells and through the tunnel of Corti $(T)$ to the three rows of outer hair cells in normal animals (arrows in $a, c)$. Fibers to outer hair cells are reduced in number, and their distribution is more patchy in the NT-3 null mice in both the middle (arrows in $b$ ) and the apical turn (arrows in $d)$. $R$, Fibers. Scale bars, $100 \mu \mathrm{m}$.

bundle (IGSB) at the level of the cochlear ganglion (see Fig. $7 b, d, f)$. From this bundle, efferent fibers project toward the sensory epithelium radially following similar trajectories as those of afferent sensory fibers. Several abnormalities are seen in the efferent projections in the cochleae of NT-3-deficient mice (Fig. $7 a, c, e)$. In the mutants, an IGSB does not seem to be present. In addition, radial efferent fibers are reduced in number at the apical and middle turns of the cochlea (Fig. $7 c, e$ ), whereas in the basal turn, where the spiral ganglion is completely absent, no intraganglionic fibers or radial fibers could be found (Fig. 7a). These abnormalities share similarities to those described above for the sensory afferent system, namely a reduction in the number of radial fibers in apical and middle turns and a complete loss in the basal turn. Moreover, as observed with the afferents, efferent fibers initially projecting toward the middle turn redistribute and project more basally to reach the inner hair cells of the basal turn of the cochlea (Fig. 7a). Furthermore, once these axons have reached the row of IHCs, they form a spiral bundle that extends along the IHC epithelium to reach the most basal IHCs. Efferent supply to OHCs was also disrupted in the cochleae of NT-3 mutants. In six different control animals, efferent fibers reaching toward the three rows of OHCs were always found in the basal and middle turns (Fig. $7 b, d$ ). Similar to the afferent innervation, the mutants displayed fewer fibers that could, nevertheless, extend equally far (Fig. 7e,f). However, in five of six different mutant animals examined, efferent fibers did not extend to the outer hair cell rows (Fig. 7a,c). In summary, efferent innervation in the mutant animals parallels the behavior of afferent fibers, reaching the basal turn of the cochlea in the form of a spiral bundle that runs along the IHCs. 

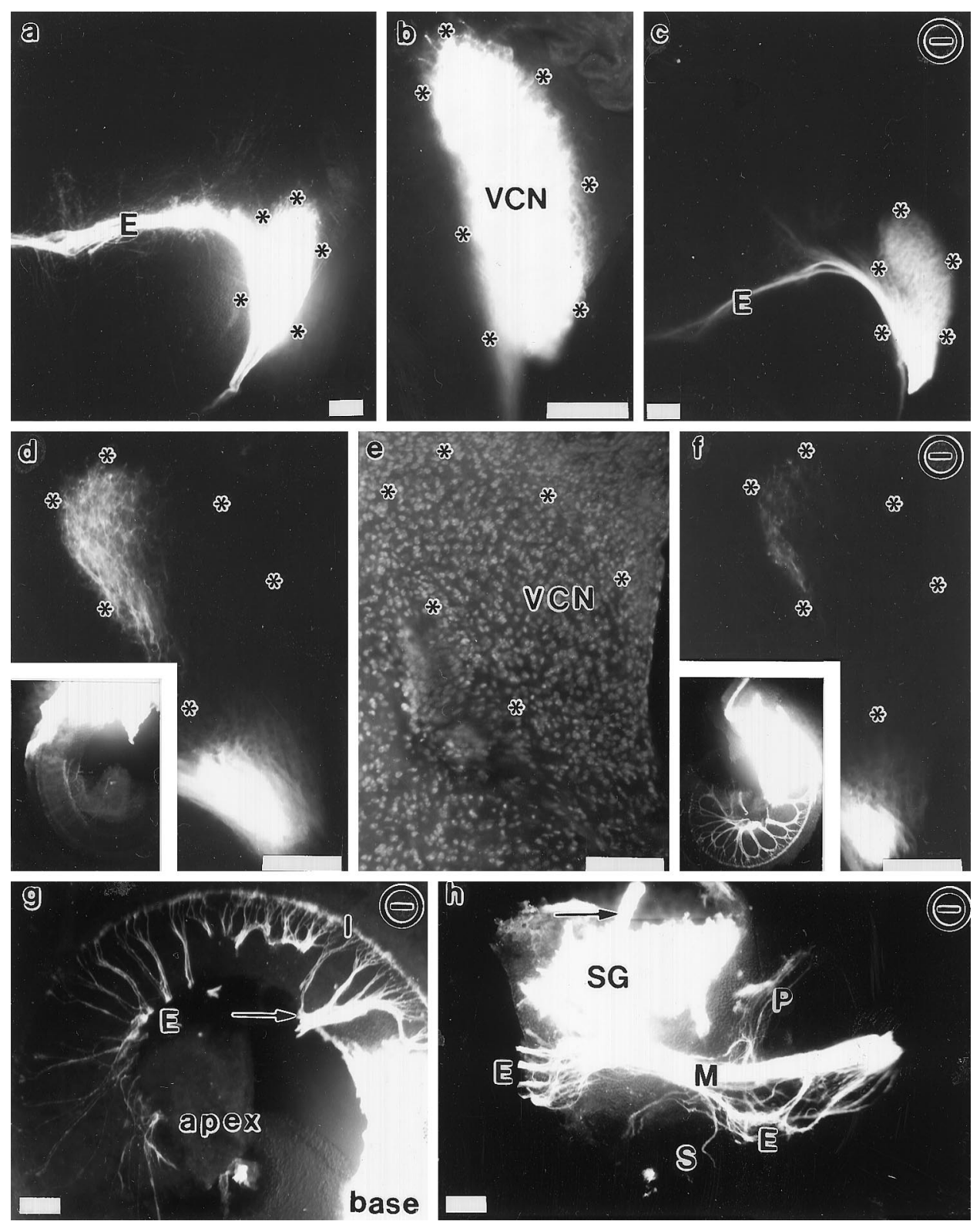

Figure 6. Comparison of afferent projections to the ventral cochlear nucleus in wildtype $(a, b, d, e)$ and mutant $(c, f)$ mice and the application site in the ear $(g, h)$. Coronal sections of brainstem labeled from the cochlea are shown $(a-f)$. Labeled cochlear afferent fibers extend throughout the ventral cochlear nucleus (VCN) in both wild-type $(a, b)$ and NT-3 mutant $(c)$ mice near the eighth nerve root. Note the apparent reduction in number of efferents $(E$ in $a, c)$ in the mutant as well as a less dense labeling near the dorsolateral aspect of the cochlear nucleus in the mutant. The cochlear projection covers the ventral cochlear nucleus (asterisks; compare $b, e$, images at two different excitations from the same section) as much in the control $(a)$ as in the NT-3 mutant littermate $(c)$. A selective projection from the basal turn ( $d$, $f$, insets) shows a comparable pattern of projection to the dorsomedial aspect of the ventral cochlear nucleus (shown in the Hoechst-stained control by asterisks in $e$ ). However, there is a reduction in fiber density in the mutant that compares with the reduced density of innervation of the basal turn of the cochlea. Closer examination of the cochlea and the spiral ganglion with the modiolus in an NT-3 mutant with a basal turn application $(g, h)$ shows numerous efferent collaterals $(E)$ extending throughout the cochlea $(g)$. In addition, spiral ganglion cells near the middle turn are labeled, as are efferent and afferent fibers in the modiolus $(M)$ and toward the brain $(h)$. Note that no ganglion neurons are labeled near the modiolus, where efferents $(E)$ diverge within the inferior vestibular ganglion toward the posterior vertical canal $(P)$ and the saccule $(S)$. The arrow indicates the same fibers from the middle turn; $E$ indicates the same efferent fascicles from the apex $(g, h)$. Scale bars, $100 \mu \mathrm{m}$.

\section{Differentiation and innervation of the cochlear sensory epithelium}

Comparing control (Fig. 8a,c,e) with NT-3 mutant littermates (Fig. 8b,d,f), light microscopic analysis of plastic sections showed that the development of the organ of Corti in the NT-3-deficient mice was approximately normal. In both wild-type and mutant cochlea, one row of IHCs and three rows of OHCs could be identified in all turns, and the differentiation of these cells appeared normal in the mutant animals. On closer examination, the greater epithelial ridge (GER), a transitory epithelium that degenerates in neonates (Lim and Rueda, 1992), appeared slightly thinner in the NT-3 mutant mice than in control littermates (40 \pm $4 \mu \mathrm{m} ; n=3$; compared with $32 \pm 4 \mu \mathrm{m} ; n=3 ; p<0.02$, one-tailed Student's $t$ test) (Fig. $8 a, b$ ). In contrast to the GER, the height and width of the differentiated sensory epithelium were not noticeably affected in the mutant mice. No differences in sensory epithelium differentiation could be found along the length of the cochlea that were not accounted for by the developmental gradient present also in the control animals; i.e., the base was more differentiated than the apex, with the middle turn being intermediate. In particular, the formation of apical specializations (Fig. 8 ), i.e., the stereocilia and the kinocilium, proceeded normally in the hair cells of mutant cochleae (Figs. 9a,b, 10a,c).

The habenula perforata are small openings near the basilar membrane that underlies the organ of Corti through which fibers enter the sensory epithelium. In light microscopy, these openings through which axons course are seen as clear spaces between epithelial cells (Fig. 8c,e). In mutant animals, these clear spaces are remarkably reduced in size or almost indistinguishable (Fig. $8 b, d, f)$. Electron microscopic analysis reveal that numerous fibers pass through the habenula perforata at all levels of the cochleae of control mice (Fig. 10b). On the contrary, axons crossing these openings are only seen in the apical and middle turns of the cochleae of NT-3 mutant mice. At the basal turn of the mutant cochleae no fibers pass through the habenula perforata, even though the structure itself is still observable as a gap between adjacent epithelial cells of the GER overlying an intact basement membrane (Fig. 10d). 

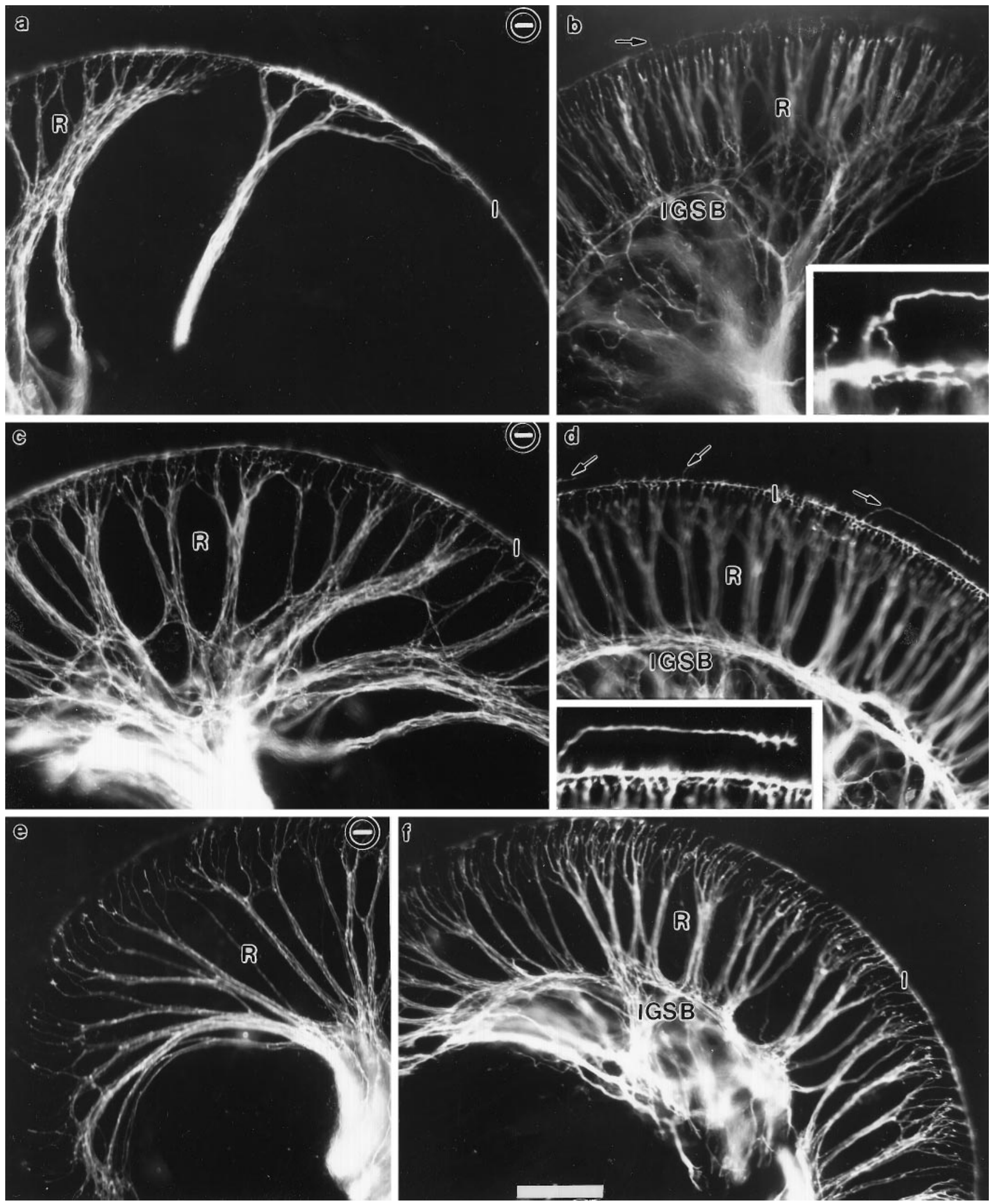

Figure 7. Comparisons of distributions of olivo-cochlear efferent fibers in newborn wild-type and NT-3 mutant mice. The distribution of olivo-cochlear efferent fibers was revealed by implanting DiI into the floor of the fourth ventricle where these fibers cross. $a, c, e$, Innervation in NT-3-/- mouse; $b$, $d, f$, innervation in corresponding regions of a control littermate. The distribution is shown for the base $(a, b)$, middle turn $(c, d)$ and apex $(e, f)$ of the cochlea. Note that the distribution of efferent fibers follows closely the distribution of afferents and shows very similar differences between the control and NT-3-/- mice. In control mice, some efferents extend to outer hair cells (d, arrows and inset). This occurs only rarely in NT-3 mutant mice (not shown). In control mice there is an elaborate network of efferent fibers within the spiral ganglion and a clear formation of IGSBs, which cannot be identified in the NT-3 mutant mice. The overall progression of efferent fibers to the apex is comparable in both normal and mutant mice (e, $f$ ), but again fewer fibers are seen in the NT-3-deficient mice $(e)$. I, Inner spiral bundle near the inner hair cells. Scale bar, $100 \mu \mathrm{m}$ for all images. 


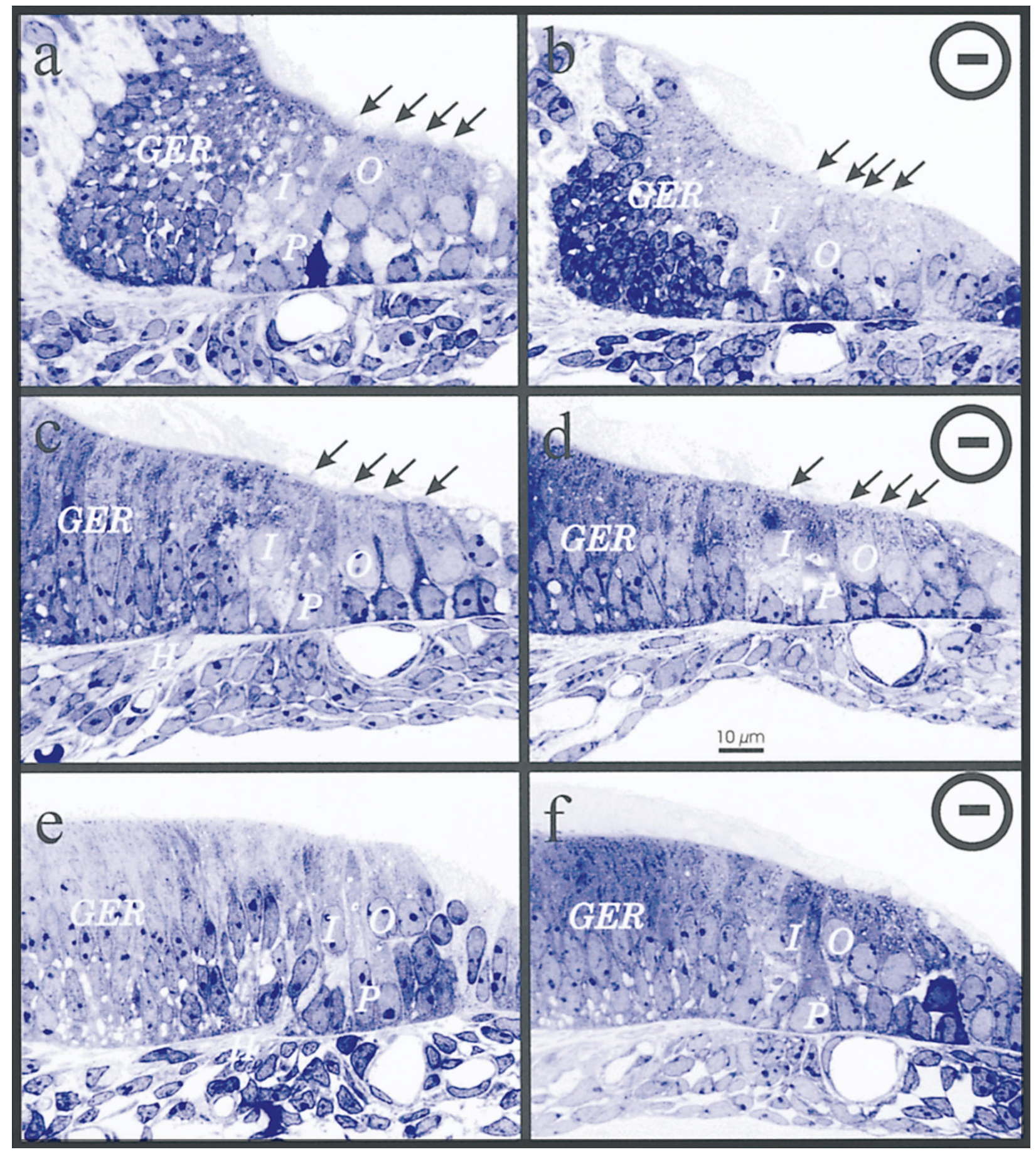

Figure 8. Differentiation of the sensory epithelium of the cochlea in normal and NT-3-deficient mice. These micrographs of 1- $\mu \mathrm{m}$-thick plastic sections taken from newborn mice show the appearance of inner $(I)$ and outer $(O)$ hair cells in the basal $(a, b)$, middle $(c, d)$, and apical turn $(e, f)$ of a control $(a, c, e)$ and an NT-3 null littermate $(b, d, f)$. Note that the only difference that is readily apparent is the height of the greater epithelial ridge (compare $a, b)$, a transitory structure that degenerates in neonates. The only other difference that is apparent is the almost complete absence of nerve fibers entering the organ of Corti through the habenula perforata $(H)$. Note that the position of the pilar cells $(P)$ is always next to the lateral wall of the spiral vessel underneath the basilar membrane. Arrows indicate the apical specializations protruding into the scala media. Scale bar, $10 \mu \mathrm{m}$ for all panels.

The synaptic organization of IHCs and OHCs was analyzed at the electron microscopic level. In wild-type animals, numerous synaptic contacts were seen on IHCs, and fibers were found near OHCs (Figs. 10, 11). A normal gradient of synaptic differentiation was evident, because synapses on IHCs in the basal turn of the cochleae of wild-type mice were more mature than in other parts. In the basal part of the cochlea, differentiated synaptic contacts on
IHCs were found in both wild-type (Fig. 11a) and mutant (Fig. $11 b$ ) animals. Consistent with the reduced distribution of afferent fibers to the rows of OHCs in different parts of the cochlea, no synapses on OHCs were seen in the basal part of mutant cochleas, although numerous close approximations between fibers and OHCs were present in wild-type and mutant mice in other regions (Fig. 11, compare $c-f$ ). There was an apparent reduction 

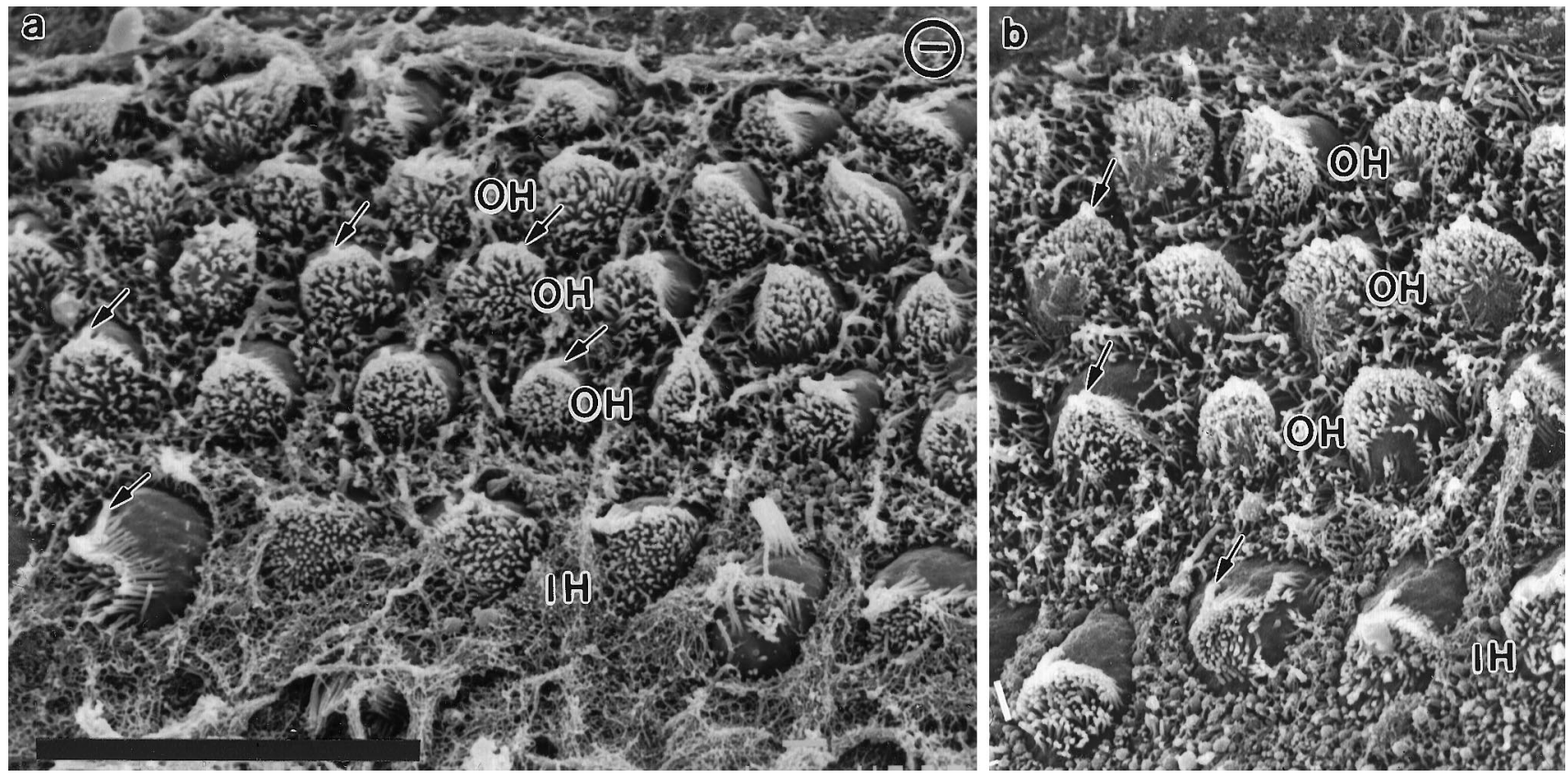

Figure 9. Differentiation of inner and outer hair cells in newborn control and NT-3 mutant mice. Scanning electron micrographs from the apical (a) and middle turn $(b)$ of an NT-3 mutant mouse $(a)$ and a control littermate $(b)$. Note that a single row of inner hair cells $(I H)$ and multiple rows of outer hair cells $(\mathrm{OH})$ are present in both preparations. The appearance of the hair cells, each of which has developed an array of apical stereocilia and a single kinocilium (arrows), appears to be the same in the normal and mutant animals. Scale bar, $10 \mu \mathrm{m}$ for both images.

in the numbers of fibers in the outer spiral bundles in the mutants compared with the control littermates (Fig. 11c,e).

In summary, our results on hair cell differentiation and fiber supply in NT-3 mutants have revealed no significant effects of NT-3 deficiency on any aspect of hair cell differentiation in neonatal animals. Differentiation seems normal even in the completely noninnervated basal $\mathrm{OHC}$ rows. Although the trajectories of the afferent sensory fibers that innervate the basal turn of the cochlea are abnormal in NT-3-deficient mice, the synapses made by these afferents on IHCs seem to have differentiated normally compared with controls. Thus maturation of synaptic contacts between IHCs and afferent fibers does not seem to be defective in the NT-3 mutant homozygotes.

In the present study we have shown that NT-3 deficiency results in dramatic but complex and region-specific effects on cochlear ganglion cell density and innervation patterns. No ganglion cells were found near the basal turn, but some ganglion cells were found near other regions of the cochlea. Despite an overall loss of $85 \%$ of the cochlear ganglion neurons, changes in projections of axons from the surviving neurons result in innervation of all IHCs where these fibers form synapses. In addition, spiral fibers reach many OHCs. Similar changes in the projection patterns of efferent axons suggest that the projection pattern of these axons is dictated in large part by the pattern of afferent projections.

\section{DISCUSSION}

Previous studies have provided strong evidence that survival of essentially all neurons in the cochlear ganglion depends on NT-3 or BDNF. These neurons are completely absent in mice homozygous for mutations in both BDNF and NT-3 (Ernfors et al., 1995) or in both $t r k \mathrm{~B}$ and $t r k \mathrm{C}$, the major receptors for these neurotrophins (Fritzsch et al., 1995, 1997a). Results in the present paper suggest that gradients of dependence on these individual neurotrophins exist within the cochlea. In particular, all neurons in the basal turn seem to require NT-3 for their survival, whereas some neurons survive in other regions of the cochlea in its absence. A similar regional loss of neurons is seen in mice lacking $t r k \mathrm{C}$, the major receptor for NT-3 (Fritzsch et al., 1995). Conversely, although the overall deficiency is less dramatic in BDNF mutant homozygotes, recent work has shown that innervation of $\mathrm{OHCs}$ is completely lost in the apical turn in these animals (Ernfors et al., 1995), whereas it is partially retained in the basal turn (Bianchi et al., 1996; Fritzsch et al., 1997b). In principal, these observations could be explained by the existence of gradients of neurotrophin expression within the cochlear sensory epithelium or by gradients of trk receptor expression within the cochlear ganglion. A basal-to-apical gradient of expression of NT-3 within the target epithelium has been observed in the cochlea at birth (Pirvola et al., 1992). Our data using the lac Z reporter show staining throughout the cochlea that is more prominent in the apex (Fig. 2). To explain the unusual pattern of innervation in the NT-3 mutants, an analysis of NT-3 expression throughout development will be necessary.

Despite the apparent absence of cochlear neurons in the basal turns of mutant cochleae, afferent fibers from other areas reach the IHCs of the organ of Corti at this level (Fig. 3c). A similar plastic phenomenon can be found, for instance, after denervation of eye muscles, in which axons of motor neurons innervating nearby muscles sprout to replace the missing innervation (for review, see Fritzsch and Sonntag, 1990). In addition, we have shown that these afferent fibers do not reach the epithelium in the form of radial bundles but instead form novel bundles with altered trajectories that reach the sensory epithelium and then adopt spiral trajectories extending along the entire length of the basal turn. These data suggest that IHCs may release an as yet uncharacterized neurotropic factor that attracts the growing neurites, as suggested by previous in vitro experiments (for review, see Bianchi and Cohan, 1993). 

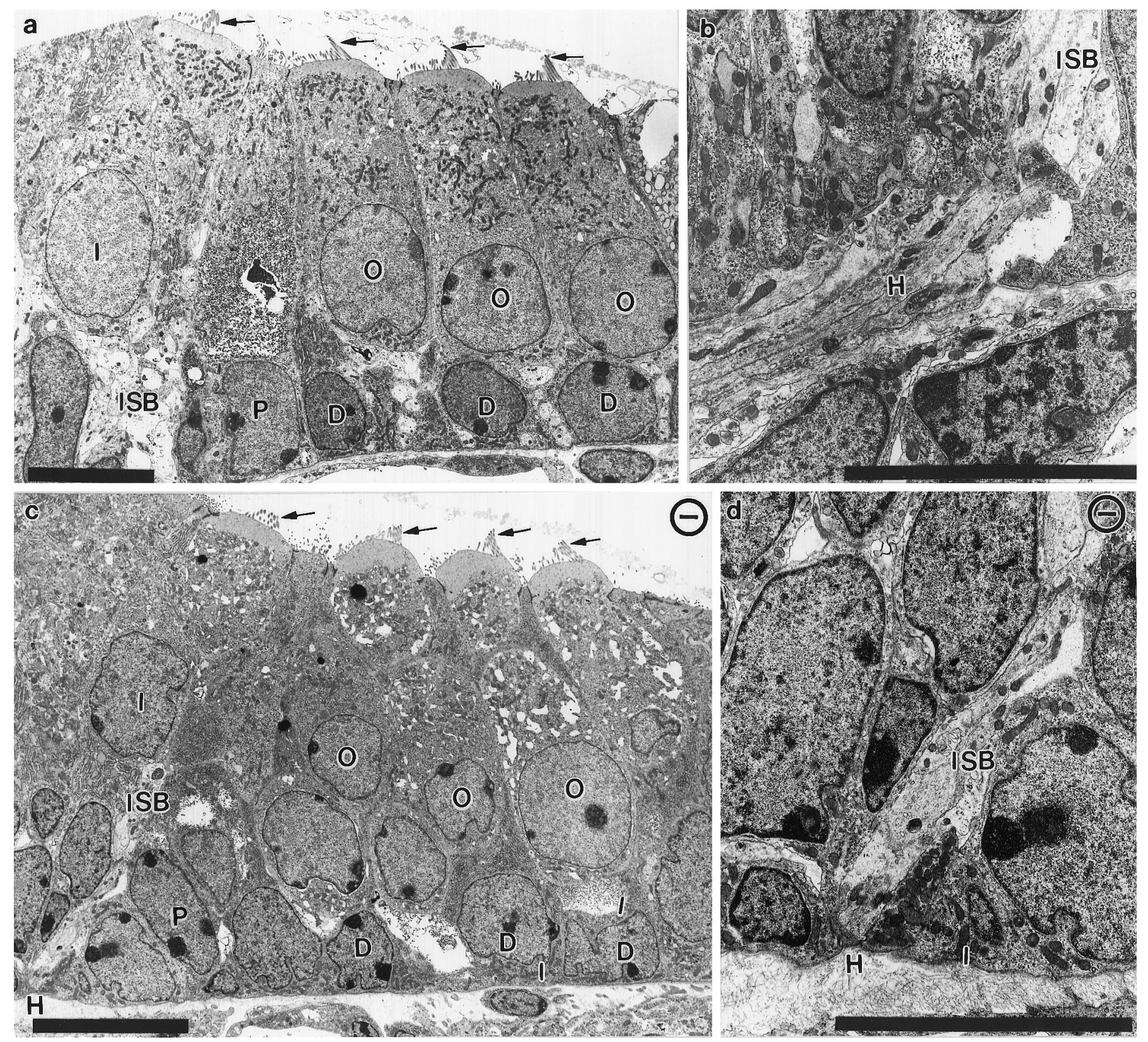

Figure 10. Transmission electron microscopic images of the organ of Corti in newborn control and mutant animals. Electron micrographs show the organ of Corti with the three rows of outer hair cells $(O)$, Deiter's cells $(D)$, one row of inner hair cells $(I)$, and pilar cells $(P)$ in control $(a)$ and NT-3 mutant $(c)$ animals. Other than the plane of the section, which is slightly oblique in $c$, there are no differences between the control $(a)$ and the NT-3 mutant littermate $(c)$. Note the presence of apical specializations in all hair cells (arrows in $a$, $c$ ). The habenula perforata $(H)$ has no fibers passing through at the basal turn of NT-3 mutant mice $(c, d)$ but has numerous fibers joining the inner spiral bundle (ISB) underneath the inner hair cell in control animals $(a, b)$. Scale bar, $10 \mu \mathrm{m}$ in each panel.

NT-3 mutant mice lose $\sim 85 \%$ of the normal complement of spiral ganglion neurons (Fariñnas et al., 1994; Ernfors et al., 1995). In normal animals, type I ganglion cells constitute the vast majority of the cochlear neurons and selectively innervate IHCs. The large neuronal loss observed in cochlear ganglia of NT-3deficient mice suggests that many type I ganglion cells are missing. It has also been reported that type II spiral ganglion neurons, a very small proportion of neurons present in the ganglion, along with their projection to OHCs, are specifically lost in BDNFdeficient mice (Ernfors et al., 1995). In addition to these partial and very different deficits found in NT-3 and BDNF single mutant mice, double NT-3-BDNF or trkB-trkC mutant mice have been shown to lose all cochlear ganglion neurons (Ernfors et al., 1995; Fritzsch et al., 1995), indicating that these neurotrophins are likely to have additive, nonoverlapping effects on the survival of these neurons. This has led to the conclusion that these two populations of cochlear neurons are each dependent on a particular neurotrophin (Ernfors et al., 1995). More recent analyses, including the present work, however, indicate that the situation is more complex than this one neurotrophin-one cell type model. Analyses of complete cochleae in BDNF-deficient mice have revealed innervation of the OHCs and actual synapses on these cells in some regions, suggesting that some type II ganglion cells survive (Bianchi et al., 1996; Fritzsch et al., 1997b). 

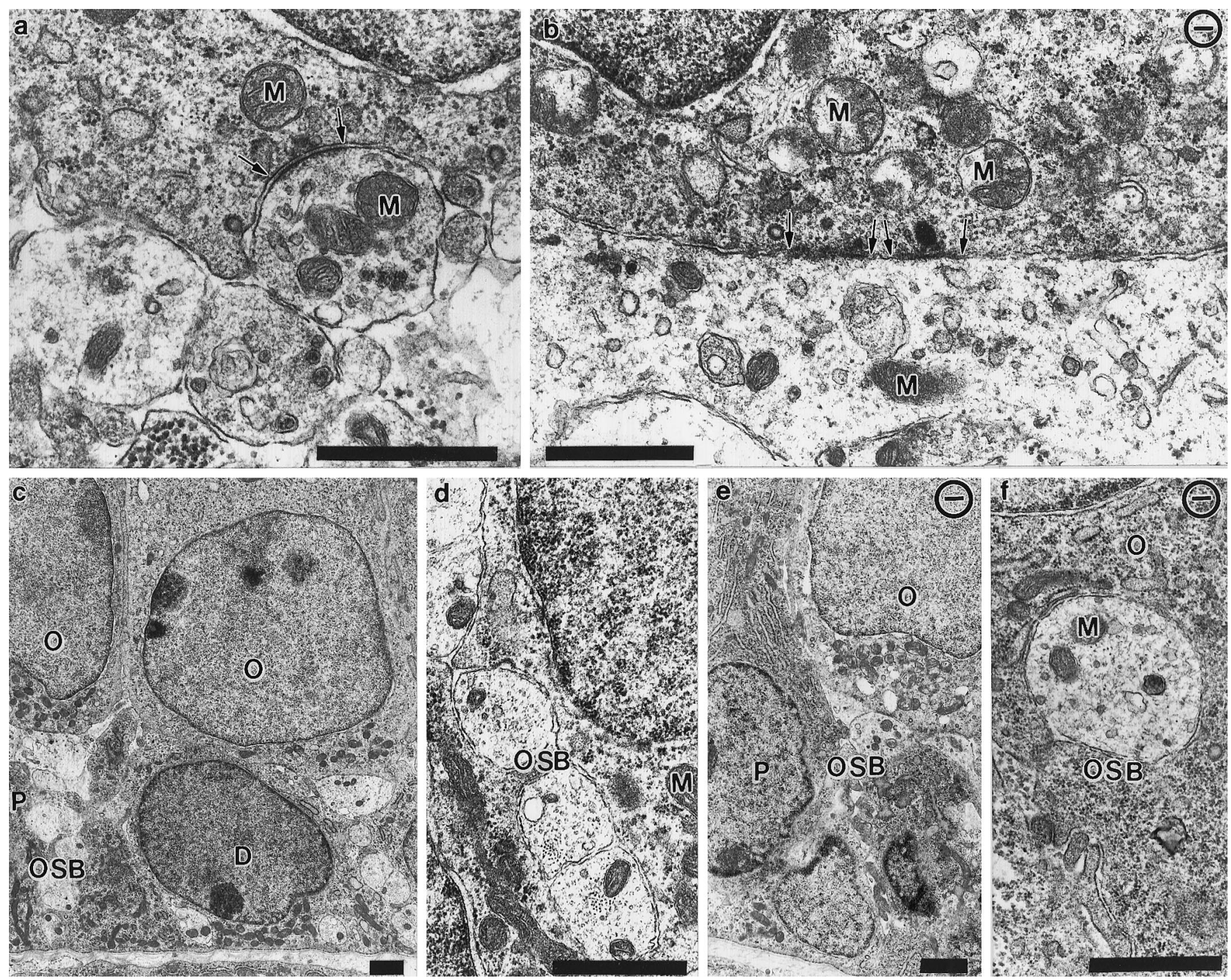

Figure 11. Electron microscopic examination of contact development in control and NT-3-deficient animals. These transmission electron micrographs show the synaptic interactions with the inner hair cells $(a, b)$ and approach of fibers to outer hair cells $(c-f)$ in a control $(a, c, d)$ and an NT-3 mutant mouse $(b, e, f)$. Inner hair cells show synaptic contact regions, which occasionally bear presynaptic bars surrounded by synaptic vesicles with adjacent fiber profiles (arrows in $a, b$ ). In contrast, the contacts are not as mature on outer hair cells and do not show clear indications of synaptic specializations. In control mice many fibers running in the outer spiral bundles $(O S B)$ are seen underneath every hair cell $(c, d)$. In the mutants, few fibers are restricted to the innermost outer hair cell next to the pilar cells $(e)$, and only a few fibers are next to the outer hair cells $(f, O)$. $P$, Pilar cells; $D$, Deiter's cells; $M$, mitochondria. Scale bar, $1 \mu \mathrm{m}$ in each panel.

Likewise, the presence of IHC innervation in the NT-3 mutant mice, as shown in this study, is likely to be a good indication that some type I ganglion cells survive.

Regarding innervation of IHC in NT-3 mutants, we have to consider, however, two other formal possibilities. First, the type II ganglion could abnormally project to IHCs in the absence of type I ganglion cells and thus generate the false impression that type I ganglion cells are still present in the cochleae of NT-3 mutant mice. At present it is not known how these two types of afferents become segregated to the IHCs and OHCs during normal development, but some studies have indeed indicated an early mix of both (Sobkowicz, 1992; Echteler, 1992). If true, this would imply that there is a heterogeneity of neurotrophic dependence of type II neurons along the cochlea. This would be consistent with the presence of type II afferents to outer hair cells in the basal turn of BDNF (Bianchi et al., 1996) and trkB (Fritzsch et al., 1997b) mutant mice. Second, a third type of ganglion cells could be present that is not affected by the lack of NT-3 and that could supply this innervation. An intermediate ganglion cell type, between types I and II, has been described in developing and some adult mammals (Lorente de Nó, 1981; Ryugo, 1992; Sobkowicz, 1992). It seems that the projections of this third type of spiral ganglion cell do extend along the IHCs in the inner spiral bundle for some distance, much like the fibers in the basal turn of the cochleae of NT-3 mutant mice. Moreover, this type of intermediate spiral ganglion cell innervates only IHCs (Sobkowicz, 1992), similar to the basal spiral fibers in the NT-3 mutant mice. Thus, there is a possibility that this intermediate type becomes more conspicuous and/or expands its normal pattern of innervation in NT-3 mutants. Nevertheless, the presence of synapses on IHCs and the extension of some fibers to OHCs strongly suggest that representatives of the two populations of sensory neurons may survive in this mutant in some parts of the cochlea, whereas all neurons of both classes disappear in the basal turn. All these 
results indicate that there is not an absolute assignment of one neurotrophin to either type of neuron. Interestingly, it seems that regional specificity may be more important in governing neurotrophin actions in the developing auditory system.

The most remarkable finding regarding the cochlear efferent innervation pattern in mice lacking NT-3 is its close similarity to the altered pattern of afferent innervation. Thus, the basal turn receives efferent fibers only via the inner spiral bundle, not via radial fibers, and only IHCs are innervated. Although analysis of individual sections in a previous report had suggested the presence of a normal efferent innervation pattern of the cochleae in NT-3 mutants (Ernfors et al., 1995), our tract-tracing studies in whole cochleae reveal a region-specific alteration of the pattern of efferent projections. The similarity in alterations of efferent and afferent innervation patterns is intriguing. A matching pattern of afferent and efferent innervation has also been reported in trkB and $t r k \mathrm{C}$ mutant mice and in homozygous trkB and heterozygous trkC mutants (Fritzsch et al., 1995). These observations suggest that efferents follow the trajectories of afferent fibers during development to reach hair cells. Central efferents reach the hair cells later than the cochlear sensory afferent projection but before birth (Sobkowicz, 1992; Fritzsch et al., 1995; Fritzsch, 1996). A more detailed investigation will be necessary to determine definitively mechanisms underlying the development of this unusual spatial pattern of efferent cochlear innervation.

It is noteworthy that lack of NT-3 has a rather limited effect on the development of the cochlear epithelium despite the loss of 85-87\% of afferents (also see Ernfors et al., 1995). Likewise, two types of hair cells differentiate in epithelia that lack all innervation in trkB mutant mice (Fritzsch et al., 1997b). The absence of detectable effects of neurotrophin deprivation on hair cell differentiation in all sensory epithelia is further supported by data derived from either BDNF-NT-3 or trkB-trkC double mutant mice in which the organ of Corti seems to develop rather normally (Ernfors et al., 1995; Fritzsch et al., 1995) compared with the available descriptions of mouse cochlear development (Lim and Rueda, 1992). Although incomplete formation and differentiation of the cochlea sensory epithelium in trkC mutant mice have been described in one report (Schimmang et al., 1995), the reported deficits seem localized to the greater epithelial ridge, a transient structure that results of the present study show is also somewhat reduced in NT-3 null mice.

In summary, our data show a selective region-specific disappearance of cochlear ganglion cells in mice lacking NT-3 and dramatic changes in the patterns of afferent and efferent innervation. In contrast to previous suggestions, our results do not support the notion that type I but not other types of spiral ganglion cells require NT-3 for survival. Instead, there seems to be a graded position dependence of all types of spiral ganglion cells on NT-3 that is most pronounced in the basal turn, in which neurons, both types I and II, are lost in mutants, but is only partial in the middle and apical turns, in which cells of both types seem to survive. There is only a reduction but not a complete loss of the afferent projection to the cochlear nuclei with a preserved cochleotopic projection. The altered pattern of efferent innervation seems to be largely a consequence of the altered pattern of afferent innervation.

\section{REFERENCES}

Berglund AM, Benson TE, Brown MC (1996) Synapses from labeled type II axons in the mouse cochlear nucleus. Hear Res 94:31-46.

Bianchi LM, Cohan CS (1993) Effects of the neurotrophins and CNTF on developing statoacoustic neurons: comparison with an otocystderived factor. Dev Biol 159:353-365.

Bianchi LM, Conover JC, Fritzsch B, De Chiara T, Lindsay RM, Yancopoulos GD (1996) Degeneration of vestibular neurons in late embryogenesis of both heterozygous and homozygous BDNF null mutant mice. Development 122:1965-1973.

Easter SS, Ross LS, Frankfurter A (1993) Initial tract formation in the mouse brain. J Neurosci 13:285-299.

Echteler SM (1992) Developmental segregation in the afferent projections to mammalian auditory hair cells. Proc Natl Acad Sci USA 89:6324-6327.

Ernfors P, Lee K-F, Jaenisch R (1994) Mice lacking brain-derived neurotrophic factor develop with sensory deficits. Nature 368:147-150.

Ernfors P, van de Water T, Loring J, Jaenisch R (1995) Complementary roles of BDNF and NT-3 in vestibular and auditory development. Neuron 14:1153-1164.

Fariñas I, Jones KR, Backus C, Wang X-Y, Reichardt LF (1994) Severe sensory and sympathetic deficits in mice lacking neurotrophin-3. Nature 369:658-661.

Fritzsch B (1996) Development of the labyrinthine efferent system. Ann NY Acad Sci 781:21-33.

Fritzsch B, Nichols DH (1993) DiI reveals a prenatal arrival of efferents at the differentiating otocyst of mice. Hear Res 65:51-60.

Fritzsch B, Sonntag R (1990) Oculomotor (N III) motoneurons can innervate the superior oblique muscle of Xenopus after larval trochlear (N IV) nerve surgery. Neurosci Lett 114:129-134.

Fritzsch B, Silos-Santiago I, Smeyne R, Fagan AM, Barbacid M (1995) Reduction and loss of inner ear innervation in trkB and trkC receptor knockout mice: a whole mount DiI and scanning electron microscopic analysis. Aud Neurosci 1:401-417.

Fritzsch B, Silos-Santiago I, Bianchi L, Fariñas I (1997a) The role of neurotrophic factors in regulating inner ear innervation. Trends Neurosci 20:159-165.

Fritzsch B, Silos-Santiago I, Bianchi L, Fariñas I (1997b) Effects of neurotrophin and neurotrophin receptor disruption on the afferent inner ear innervation. Semin Cell Dev Biol 8:277-284.

Jones KR, Fariñas I, Backus C, Reichardt LF (1994) Targeted disruption of the brain-derived neurotrophic factor gene perturbs brain and sensory but not motor neuron development. Cell 76:989-100.

Lazik A, Liu Y, Bringas P, Sangiorgi F, Maxson R (1996) A sensitive method for analyzing $\beta$-galactosidase reporter gene expression in tissue sections of mouse embryos. Trends Genet 12:445-447.

Lim DJ, Rueda J (1992) Structural development of the cochlea. In: Development of auditory and vestibular systems 2 (Romand R, ed), pp 33-58. Amsterdam: Elsevier.

Lorente de Nó R (1981) The primary acoustic nuclei. New York: Raven.

Pirvola U, Ylikoski J, Palgi J, Lehtonen E, Arumae U, Saarma M (1992) Brain-derived neurotrophic factor and neurotrophin 3 mRNAs in the peripheral target fields of developing inner ear ganglia. Proc Natl Acad Sci USA 89:9915-9919.

Pirvola U, Arumae U, Moshnyakov M, Palgi J, Saarma M, Ylikoski J (1994) Coordinated expression and function of neurotrophins and their receptors in the rat inner ear during target innervation. Hear Res 75:131-144.

Romand MR, Romand R (1987) The ultrastructure of spiral ganglion cells in the mouse. Acta Otolaryngol (Stockh) 104:29-39.

Ryugo DK (1992) The auditory nerve; peripheral innervation, cell body morphology, and central projections. In: The mammalian auditory pathway: neuroanatomy, Springer handbook of auditory research (Webster DB, Popper AN, Fay RR, eds), pp 23-65. New York: Springer.

Schecterson LC, Bothwell M (1994) Neurotrophin and neurotrophin mRNA expression in developing inner ear. Hear Res 73:92-100.

Schimmang T, Minichiello L, Vazquez E, San Jose I, Giraldez F, Klein R, Represa J (1995) Developing inner ear sensory neurons require TrkB and $\mathrm{TrkC}$ receptors for innervation of their peripheral targets. Development 121:3381-3391.

Sobkowicz HM (1992) The development of innervation in the organ of Corti. In: Development of auditory and vestibular systems (Romand R, ed), pp 59-100. Amsterdam: Elsevier.

Walsh EJ, Romand R (1992) Functional development of the cochlea and the cochlear nerve. In: Development of auditory and vestibular systems 2 (Romand R, ed), pp 161-219. Amsterdam: Elsevier.

Wheeler EF, Bothwell M, Schecterson LC, von Bartheld CS (1994) Expression of BDNF and NT-3 mRNA in hair cells of the organ of Corti: quantitative analysis in developing rats. Hear Res 73:46-56. 